\title{
An Analysis of Challenges obstructing Growth of SMEs in the South African Tourism Sector: A theoretical evaluation
}

\author{
Bongani Mwale and Steven Shabangu \\ Mbombela, South Africa
}

\begin{abstract}
The study empirically sought to analyse challenges inhibiting the growth of Small and Medium Enterprises (SMEs) within the tourism sector in South Africa. The study employed qualitative research design following the in depth interviews in order to gather data form tourism SME owners and managers in South Africa, who formed the sample population for the study. A sample of 20 respondents was drawn using purposive sampling approach. The participants who were selected were tourism SME owners and managers of guesthouses, lodges and bed and breakfast houses, shuttle transport, art and craft curio shops and agricultural sector. The researchers has provided a perspective on the role of tourism SMEs in South Africa. The study identified the hindering challenges for tourism SMEs development and growth as lack of access to funding, inadequate or unavailable government funding, lack of entrepreneurial and management skills to operate their businesses, lack of networking connections, poor location of SME operations and stiff competition for well-established SMEs. The recommendations were made that alternative funding strategies should be used, SME owners and managers should be trained, the SMEs should join network groups and share ideas, and they should also invest in marketing and communication technologies for their products to be known to the market.
\end{abstract}

Keywords: Small and Medium Enterprises, tourism, economic growth, inclusive growth

DOI: $10.7176 / \mathrm{EJBM} / 12-22-06$

Publication date:August $31^{\text {st }} 2020$

\section{Introduction}

Reducing inequality and unemployment and eliminating poverty are key goals of the National Development Plan (NDP) for South Africa by 2030 (Statistics South Africa, 2016). The current economic climate of South Africa shows a substantial gap with these goals. While the incidence of unemployment rate is at 32 percent, poverty is at 67 percent (Statistics South Africa, 2018). Reports have shown that South Africa is one of the most unequal countries in the world, as shown by the Gini coefficient of 0.691 and this has not significantly changed since the new dispensation in 1994 (National Treasury Research, 2016). Acceleration of inclusive growth is therefore crucial if South Africa is to realise significant reductions in poverty, inequality and unemployment. One of the growth strategies that South Africa could employ to achieve this is the development and growth of entrepreneurship, with special attention to SMEs in the tourism industry. Even though the development and growth initiatives have been on the policy agenda of government since 1994, little success has been registered for tourism SMEs (National Development Plan 2030, 2012; National Planning Commission, 2012)

The key objective of this study was to investigate challenges faced by the tourism Small, Medium and Micro Enterprises SMEs in South Africa in tourism industry. The study was conducted to explore the challenges for SMEs for tourism with focus to all possible hindrances faced by people from previously disadvantaged groups following the Government of South Africa's policy commitment to support the tourism SMEs (Chili and Mabaso, 2016). This article therefore sought to explore how the developing tourism SMEs in South Africa should have been undertaken. It is from this backdrop that this study will suggest possible solutions will mitigate the identified challenges.

Most literature that has been reviewed has indicated that most success of development of SMEs in tourism had taken place in developed countries (Ateljevic and Dooorne, 2004). In other developing countries there was evidence of similar success registered (Rogerson, 2017). Although these assertions have been made about SMEs in other developing countries, in South Africa, there is little empirical evidence on tourism SMEs (Hlengwa, 2018). According to the estimation conducted by the National Treasury Research (2016) which established that a number of SMEs in the country exceeded three million and could exceed number of people employed by public and private sector combined together. The significance that SMEs have in the economy has not seen fruition due the higher rate of failure, which was approximated to be $75 \%$ with most SMEs failing to survive beyond three and half years (National Treasury, 2013). It was also observed that, those that survived remained in the infancy stage for very long time. There has not been any evidence for this failure, and this study sought to explore the challenges faced by the tourism SMEs in South Africa.

The significance of this study is that SMEs have been observed to contribute greatly to the economic growth of economies both in developed and in developing countries (Smith, 2017). Governments are therefore developing strategies to grow and sustain of SMEs with focus on tourism (Ribeiro-Siriano, 2017). Even though tourism SMEs play a key role in contributing to economies through employing a multiplicity of skills, the growth of tourism 
SMEs had been revealed to be difficult (Koens and Thomas, 2015). In South Africa tourism SMEs account for $40 \%$ to GDP, and they are expected to be the future of business by 2030 (Smith, 2017). The attainment of this vision will not be realised considering the current slow growth of the tourism SMEs. This study sought to explore the challenges faced by the tourism SMEs in order to inform decisions of policy makers and the tourism SMEs owners.

\section{Literature Review}

\subsection{Tourism World Wide}

Several reports have been produced which gave evidence of the decline in tourism in America since the assumption of Donald Trump's presidency (Coldwell, 2017; Glusac, 2017). These reports indicated steep declines in travel of $58 \%$ from UK: to Orlando and Tampa, $52 \%$ to Miami, $43 \%$ to San Diego and $32 \%$ to Los Angeles. In Africa, tourism was expected to be the driver of inclusive and transformative growth considering the rapid increase in international travel which recorded 18.7 million in 2017, a growth rate of 7\% from 2012 (Coldwell, 2017). Hopes for sustained tourism business to major tourist destinations, were raised in 2017, when an increase of $6 \%$ was recorded between January and April (Robano, Leal and Karakousis, 2017).

In the Asian countries like India, tourism was promoted for the purpose of earning foreign currency and creating employment (Bhorat et al., 2018). In many of these Asian countries, for instance Malaysia, tourism was regarded as a growth strategy and has exerted positive economic development outputs. Similarly, the remote Australian communities have seen tourism as a source of community livelihood and economic growth strategy (United Nations, 2020).

\subsection{Tourism in South Africa}

In South Africa, tourism growth and development has been the major topic on policy agenda since the advent of the new dispensation in 1994 (Rogerson, 2017). Many tourism initiatives have been debated for piloting and implementation in order to increase the country's economic growth and global market share. Similar to other countries, South Africa has also considered tourism SMEs to be a driver for economic growth and sustainer of livelihoods (Siddo, 2017). Though this view point was shared by economists, experts and policy makers, there was empirical evidence of the little entrepreneurial activity in South Africa, by comparison with other countries like Brazil, Chile, Zambia and Ghana (United Nations, 2020). The same report has indicated that South continued facing difficulties to achieve a more sustained and robust growth path that was needed in enhancing the living standards across the country, considering that the growth rate for the GDP was less than .5\% in 2019. A step change was needed for tourism SMEs development and growth for the country to achieve its 2030 target of $90 \%$ contribution to GDP. The attainment of this goal remained below potential in the midst of high unemployment, energy shortages and weak investment. The GDP for the country was projected to remain negative in the face of limited fiscal policy space, policy uncertainties and weak business sentiment, which have contributed to feeble prospects for vigorous growth in the economic growth in general, and in tourism sector in particular.

\subsection{Benefits of Tourism SMEs}

Tourism benefits many stakeholders through direct and indirect connections by inducing major processes, procedures and functions of local, regional, national and international organisations. It involves multiple diverse and widely varied skills which induce earning opportunities (Scowsill, 2017; Siddo, 2017). From this point of view, many researchers have regarded tourism as a driver for socio -economic growth and inclusiveness activity which has a redistribution effect (Alhowaish, 2016; Scowsill, 2017; Statistics South Africa, 2018). Many benefits have been associated with tourism as compared with other sectors. Ohlan (2017) asserted that tourism resulted in the creation of jobs, creation of new businesses and increase in household income. Alhowaish (2016) added that tourism led development and refurbishment of the countries' infrastructures and Hlengwa (2018) expressed that tourism boosted foreign exchange reserves through increased exports, and it was the fourth largest export in the world after fuels, chemicals and food. Alhowaish (2016) further stated that tourism provided a platform for the people from different cultures to meet and mix and create new subcultural initiatives. This has prompted the development of just, fair, enlightened and humane order to be built. Ohlan (2017) reiterated that, tourism resulted in the protection of the environment, and the development of new smart technologies which promote industrial development and production, as well as increased the investment of skills development which has increased competitiveness and sustainability in the sector. It was from these assertions that Shakouri et al. (2017) noted a positive relationship between tourism and economic growth.

\subsection{Challenges Facing Tourism SMEs}

A number of reasons have been attributed to the challenges obstructing the growth of SMEs, and these were classified as endogenous and exogenous challenges. Endogenous impediments were internal challenges to the firm while exogenous impediments were caused by factors external to the SME (Shakouri et al., 2017). A collective of these challenges included: limited expertise; inadequate financial resources; poor location of SMEs, lack of 
government support; lack of management skills; inability to access formal social and business networks, lack of knowledge about branding, poor marketing techniques, stiff competition from the established SMEs, limited business environmental knowledge; and lack of experience in managing businesses among others (Ramukumba, 2018).

\section{METHODOLOGY}

Qualitative research methodology was used for this study. The main reason for conducting a qualitative research was to exploit its ability to gain the insights into the entrepreneurs' experiences, attitudes, perceptions and feelings on the challenges they faced. In depth interviews were used in gathering primary data. The interviews sought to examine the sources of challenges faced by the SMEs.

The interviews targeted the SMEs owners and managers in Gauteng, South Africa, as a target population. Purposive sampling method was used to select the 20 respondents who took part in the interviews. All the respondents were owners or managers of tourism SMEs, which included the guest houses, bed and breakfast lodges, shuttling transport, the arts and crafts, and agricultural sectors.

\section{Findings on impediments and Challenges faced by Tourism SMEs}

This section represented the findings from the interviews that were conducted on the challenges faced by tourism SMEs in their attempts to run their businesses. The results indicated that tourism enterprises were confronted with more challenges than the enterprises in other sectors.

The researchers asked the respondents to identify the challenges they faced through making lists. The challenges which appeared on most of the lists made included the following impediments: lack of capital for expansion, lack of or inadequate government support, lack of markets, unfair treatment from the local authority, lack of managerial skills and training, lack of knowledge on the latest technology, inability to access formal social and business networks, lack of knowledge about branding, marketing techniques, stiff competition from the established SMEs, and poor location. The results showed that these different challenges faced by SMEs in South Africa needed to be addressed. The challenges listed above were the themes that were further interrogated by the researchers. Each of these challenges are discussed below.

In explaining the responses in detail there were deeper insights which were revealed. The interviews disclosed that tourism entrepreneurs were worst affected by poor access to funding suggesting that capital markets and marketing support were not helping. These respondents indicated the absence of finance for business working capital as well as for acquisition of property, plant and equipment. The inability to access sources of finances forced SMEs to use their own savings at start-up, while others used monies that were given to them at retrenchment or from their inherited estates from relatives, parents and husbands.

Most of the SMEs indicated that they lacked appropriate experience to run their businesses and manage their finances. The report found out that very few of the SMEs kept financial books and accounts, and they did so without being assisted, which caused inaccurate records. The major reason for poor record keeping was caused by non-provision of financial literacy education to SME owners.

Another key challenge revealed was that the SME owners failed to seek business advice from elsewhere, but they relied only on themselves. The SME owners, who managed to get advice, got it from family and friends who also lacked hands on experiences in tourism SMEs, while others indicated that they had poor strategies to cope with adversities that threatened their businesses.

Entrepreneurs found it difficult to secure funds from lenders since those lenders found the SME entrepreneurs less attractive because they were perceived as high risk defaulting clients for lack of borrowing collateral. Banks and other financial institutions lending money created barriers which made it difficult for SMEs to access credit. The SME owners who indicated that they had access to credit pointed that it was available at exorbitant rates, as banks mitigated risk of default and bankruptcy.

Most tourism SMEs expressed that they were not aware or informed about the existing private and government financial support programs that were available for tourism SMEs. Most of the entrepreneurs who were interviewed had at one point applied for financial support from private and government, but they had not succeeded. Some pointed that when they applied for finances from these sources, a business plan was required and they had no idea how it was prepared. Other credit applications had been rejected on the basis that the business plans were inadequate or substandard. In addition, the respondents pointed out that when they were applying for credit, they got frustrated by the lack of knowledge that was demonstrated by people who were helping them. When they applied to government agencies, the agencies referred them to private agencies, did the same, making the SME owners to go in circles. The SMEs indicated that, they were treated in ways that frustrated them because they lacked collateral security required to guarantee the credit, and more so, they lacked credit records. Very few institutions have been observed to assist SMEs. These included the Department of Tourism Authority and the Small Enterprises Development Authority that supported the SMEs to take part at international tourism exhibitions and shows, through the Indaba held at the International Conventional Centre. 
The other challenge that faced the SME owners was that they came from the background disadvantaged by the apartheid legacy, which denied them access to skilled work and excluded them from meaningful economic participation. The participants blamed the apartheid-era legacy for high levels of illiteracy, underemployment and absence of skills training. Similarly, the unemployed youths raised in families that did not have operational SMEs did not have access to hands on experience to prepare themselves for their running own businesses. Lack of role models to expose family members to tourism SMEs opportunities down played the potential for SME skills development.

A further accusation levelled against apartheid legacy was that, it had not promoted the accumulation of wealth in the hands of the Africans. It was from this backdrop that the SME owners lamented that they lacked the assets required, not only to run operations, but to use as collateral security when applying for funds from financial institutions. The respondents also hinted that that these disadvantages from the previous regime were still manifesting in the labour markets where the Black youths were still being prejudiced. It was also revealed that tourism SMEs did not have better opportunities such as access to information. The respondents pointed at the wellestablished SME were barriers to the growth of infant tourism SMEs. Worse still, the well-established tourism SMEs were not prepared to share with the new operators.

When the respondents were asked whether they had any SMEs network opportunities which could facilitate them to access operations resources they required for daily operations for their businesses, most indicated that they did not know of any. Those who said that they knew the networks stated that they did not have much time to spend on social activities, because they seemed hopeless that they could not assist them to obtain funds from commercial banks. The respondents who indicated that they spend more time on social networking and social activities had obtained funds from financial institutions.

The respondents were asked whether they were aware of any government support for tourism SMEs and whether it was adequately promoting the sustainability of the entrepreneurial ventures. While some respondents indicated that they were not aware of such government support centres or initiatives that supported entrepreneurial businesses, those that indicated that they knew there was such support from the government existed, or they had once received the support, highlighted that the support was not adequate. In addition, the respondents indicated that, new tourist SMEs could succeed significantly if they received some supported from well-established SMEs.

The respondents were asked whether their businesses were located in good locations for them to thrive. Some indicated that their poor locations and infrastructure were a barrier to their tourist SMEs growth. Some revealed that, their businesses were in places where there was no electricity, poor transport and poor telecommunication networks. Some respondents indicated that their guesthouses and bed and breakfast businesses were located in places where white clients found it difficult to patronise due to crime and insecurity.

The other challenges revealed by the respondents were that they faced daunting task just to register their tourism SME businesses to obtain an operating licence. Without a licence, operations were considered illegal and that resulted in frequent visits from the municipal authorities demanding closure of the business. It was also revealed that, in some cases, authorities charged exorbitant fines when the tourism SMEs operated without the required licences. In addition, unregistered SMEs were not eligible to apply for finances from financial institutions.

The SME owners also complained that the demand for their products and services was very low, and this was attributed to high unemployment and poverty levels in the country, especially during the COVID-19 lockdown period. Another challenge came from stiffer competition from larger and well-established tourist SMEs. Due to their lack of marketing skills, the respondents indicated that, they had little idea about how they could create demand for their products and fight off competition from the established competitors. This inability was an indication that the tourism SME owners and managers lacked entrepreneurial orientation and innovative ideas.

Some of the tourist SME owners or managers lacked skills, knowledge and experience and this challenge hampered the success of their businesses. They lacked experience or skills that was needed to operate their ventures, and some revealed that they had just started their ventures, some out of frustration of failing to secure jobs, others from early retirement packages, while others said it was from loss of the bread winners. All these situations had not given the SME owners time to learn tourism skills or gain experience. Most SME owners were not equipped with the correct managerial competencies or appropriate entrepreneurial skills that were required to succeed.

\subsection{Impacts of Challenges on Tourist SMEs}

When the participants were asked about the impacts of the challenges that have been identified above, they expressed their feelings as follows:

To remain competitive in the face of the well-established ventures, some reported that they had resorted to unscrupulous business techniques in order to increase their profit margins. Such activities included buying and selling counterfeit or substandard goods in an attempt to reduce the cost of acquiring cheaper inputs for their businesses.

The tourism SME operators indicated that they had to serve alcohol outside the licenced permitted hours and hide the income accrued from this to avoid paying taxation to improve their profit. Some of the tourism SMEs 
stated they also appointed foreigners from neighbouring countries who did not have work permits to avoid paying the minimum wage promulgated by government as some foreign workers, out of desperation, were willing to settle for lower wages. Consequently, the tourism SME operators did not register and contribute towards the unemployment insurance fund for the foreign workers.

The tourism SME operators indicated they operated in markets where their customers had higher buyer bargaining power which they leveraged to negotiate prices down. This forced the tourism SMEs to operate on very thin margins which threatened their survival and profitability as they marked down prices. In response, the tourism SME operators resorted to produce and selling substandard products and services in an attempt to save costs. This strategy made customers to lose confidence in SMEs' products and in return, they took away their custom to competing SMEs. This led to reduced business and eventual closure of such SMEs.

Since people who had failed to secure formal employment founded some SMEs, the challenges faced by these operations led to closure of some of the SMEs. Increased unemployment rate in the country has forced the youths into illegal business operations. The SMEs have resorted to produce substandard products in order to reduce the costs of operations, yet they created a setback to the country as some of these counterfeit products found their way across international boundaries ruining the reputation of the country as its products would be condemned by foreign buyers.

\section{Conclusion and Recommendations}

\subsection{Conclusions}

Research has shown that SMEs were key to the advancing of an all-inclusive development and growth of the South African economy as spelt out in the National Development Plan. SMEs were highlighted by the government as important for the creation of jobs, competitiveness and innovation. It was envisioned in the National Development Plan that SMEs will create $90 \%$ of new jobs for South Africa by 2030 . The economic role of the SMEs has, however, been marginalised to the extent that the environment in which they operated was not conducive for a resounding success. If the goal for the SME to create jobs should be achieved, an appropriate policy intervention was required to assist SMEs to overcome the challenges impeding the success of their operations.

While tourism SMEs were constrained, the degree of constraints differed across ownership of SMEs. Specifically, two distinct groups of SMEs were identified as well-established SMEs with highly skilled ownerships and well financed, whereas the infant SMEs were owned by low-skilled individuals and were poorly financed.

This article identified different challenges that impeded tourism SMEs. These included funding, skills, networks, markets and location. The operations which were at their embryonic phase tended to experience more challenges than those which were well established. There is a need for a set of nuanced set of policies that cater for different categories of SMEs in order to achieve an equal growth and a more inclusive agenda.

Various support infrastructures for SMEs should be put in place so that smaller tourism SMEs would be able to survive and poverty could be reduced. The support that should be given should take the SMEs beyond mere survival, but should enable them to create employment and increase earnings.

SMEs have demonstrated that they have the potential to become a sustainable strategy for increasing and distributing wages in order to reduce inequality. A prerequisite for this was an enabling environment, which minimised the growth constraints. Broad interventions are required to enable tourism SMEs in overcoming the shared impediments where growth constraints are binding SMEs uniformly. It is also recommended that, where the constraints differed according to other SME criteria, policies required to mitigate the constraints to growth should be carefully tailored and targeted.

\subsection{Recommendations}

It is recommended that to reduce the impacts of the challenges faced by tourism SMEs, training and entrepreneurship education should be conducted. Most SMEs owners showed that they lacked entrepreneurial and managerial competences. The government should take the onus to improve entrepreneurial capacity among tourism SMEs through strengthening and expanding tertiary education especially in SMEs development and managing growth. SMEs owners could be encouraged to exploit the use of skill competences and managerial programmes that were offered by government agencies.

It can also be suggested that networking colloquiums could be organised for SMEs owners so that they participated and shared their experiences and testimonies on their successes, and on the challenges they faced in growing and sustaining their businesses. This would assist them to help one another to generate possible solutions.

The government may deal with reluctant commercial banks that were refusing to offer SMEs loans who lacked collateral security, by developing a supporting regulatory and legal framework that protected tourism SMEs from exorbitant interest rates and providing collateral to banks.

It is recommended that competition should be promoted through promulgating an effective regulatory and legal framework that does not excessively restrict licensing requirements. In the same vein, laws should be promulgated to allow regional and international banks to create better lending terms for SMEs that required capital 
for market entry. More so, the problems of requiring collateral security and lending issues could be mitigated by SMEs and policymakers considering the adopting to use the Grameen Bank-type model (GBM), where small groups were voluntarily formed by the underprivileged people so that they could obtain loans when they did not have collateral security. A more collaborative and cooperative way was required to deal the challenge of limited access finance faced by SMEs.

It can also be suggested that the government should provide more support to tourism SMEs owned and managed by Africans since they are crippled by inherent disadvantages of being born or raised in families where there were no business role models to mentor them into the entrepreneurial world.

Tourism SMEs were recommended to adopt communication and information technologies for their businesses since the development of communication and information technology was core in business for facilitating trade and for production in both local and international markets.

The government is recommended to provide everything possible that would improve the business environment in for the tourism SMEs through improved infrastructure. The infrastructure that should be provided by the government include communication technologies, road networks and buildings.

It was the responsibility of the government to create environments which allowed or promoted the emergence of new enterprises, growth of existing ones, and facilitate the coexistence of small and large enterprises such that they supported each other. The government can encourage the SME owners to enrol for incubation in private or public incubators that are found in various parts of the country. In incubations, the incubatees will be trained to develop end grow their businesses in a more sustainable manner.

\section{References}

Alhowaish, A. K. (2016). Is tourism development a sustainable economic growth strategy in the long run? Evidence from GCC Countries. Sustainability, 8 (7).

Ateljevic, I. and Dooorne, S. (2004). Diseconomies of scale: a study of development constraints in small tourism firms in central New Zealand. Tourism and Hospitality Research, 4.

Bhorat, H., Asmal, Z., Lilenstein, K., and Van Der Zee, K. (2018). SMMEs in South Africa: Understanding the constrains on growth and perfomance. University of Cape Town: Development Policy Research Unit.

Chili, N. S. and Mabaso, L. S. (2016). The challenges of developing small tourism enterprises in townships: Case of Umlazi, South Africa. Problems and Perspectives in Management 14(1): 201-205.

Coldwell, W. (2017). US tourism experiences a "Trump slump". The Guardian: International Edition. Available from: https://www.theguardian.com/travel/2017/feb/28/us-tourism-experiences-a-trump-slump.

Glusac, E. (2017). International tourism to U.S. declined in early 2017. USA: The New York Times. Available from: https://www.nytimes.com/2017/09/19/travel/tourism-united-states-international-decline.html.

Hlengwa, D. C. (2018). Crucial for economic growth, nonetheless facing numerous challenges : Tourism SMMEs within uMsunduzi Local Municipality, 7(1): 1-16.

Koens, K. and Thomas, R. (2015). Is small beautiful? Understanding the contribution of small businesses in township tourism economic development. Development Southern Africa, 32(3).

National Development Plan 2030. (2012). National Planning Commission. Pretoria. Available from: file:///C:/Users/phoswak/Downloads/NPC National Development Plan Vision 2030 -lo-res.pdf

National Planning Commission. (2012). National Development Plan 2030: Our future-make it work. Presidency of South Africa, Pretoria, 1.

National Treasury. (2013). How can South Africa meet the challenge of supporting small business. Budget Review.

National Treasury. (2016). Response to the OECD's 2016 Economic Report. Pretoria.

National Treasury. (1999). Public Finance Management Act, 01 of 1999. Available from: http://www.treasury.gov.za/legislation/PFMA/act.pdf

Ohlan, R. (2017). The relationship between tourism, financial development and economic growth in India. Future Business Journal, 3(1).

Ramukumba, T. (2018). Overcoming SMEs challenges through critical success factors: A case of SMEs in the Western Cape Province, South Africa. Economic and Business Review, 16(1).

Ribeiro-Siriano, D. (2017). Small business and entrepreneurship: Their role in economic and social development.', Entrepreneurship \& Regional Development, 29(1-2): 1-3.

Robano, V., Leal, S. and Karakousis, V. (2017). United Nations World Tourism Organisation. Financing sustainable development in tourism SMEs. Sustainable Tourism Programme. Available from: cf.cdn.unwto.org $>$ all $>$ files $>$ docpdf.

Rogerson, C. M. (2017). The economic geography of South Africa's international tourism industry. Acta Universitatis Danubius, 13(2).

Scowsill, D. (2017). Travel and tourism economic impact 2017. The World Travel and Tourism Council. Available from: available: http://www.wttc.org.

Shakouri, B. et al. (2017). International tourism and economic growth and trade: Variance decomposition analysis. 
Journal of Tourism \& Hospitality, 6(3).

Siddo, S. (2017). Transforming the South African tourism industry through SMME development. SME Tradelinks: Presentation to the inaugural SANPark tourism confernece. Available from: https://www.sanparks.org/assets/docs/events/tourism-investment-summit/transforming-the-south-africantourism-industry-through-smme-development.pdf.

Smith, W. (2017). SMMEs contribute $36 \%$ to economy. Business Report. Available from: https://www.iol.co.za/business-report/opinion/smmes-contribute-36-to-economy-8269623.

Statistics South Africa. (2018). Annually Labour Force Survey. Pretoria. Available from: http://www.statssa.gov.za/.

Statistics South Africa. (2016). Annually Labour Force Survey. Pretoria.

United Nations. (2020). World Economic Situations and Prospects. 